\section{Healthy Subjects}

BAL $x$ OW
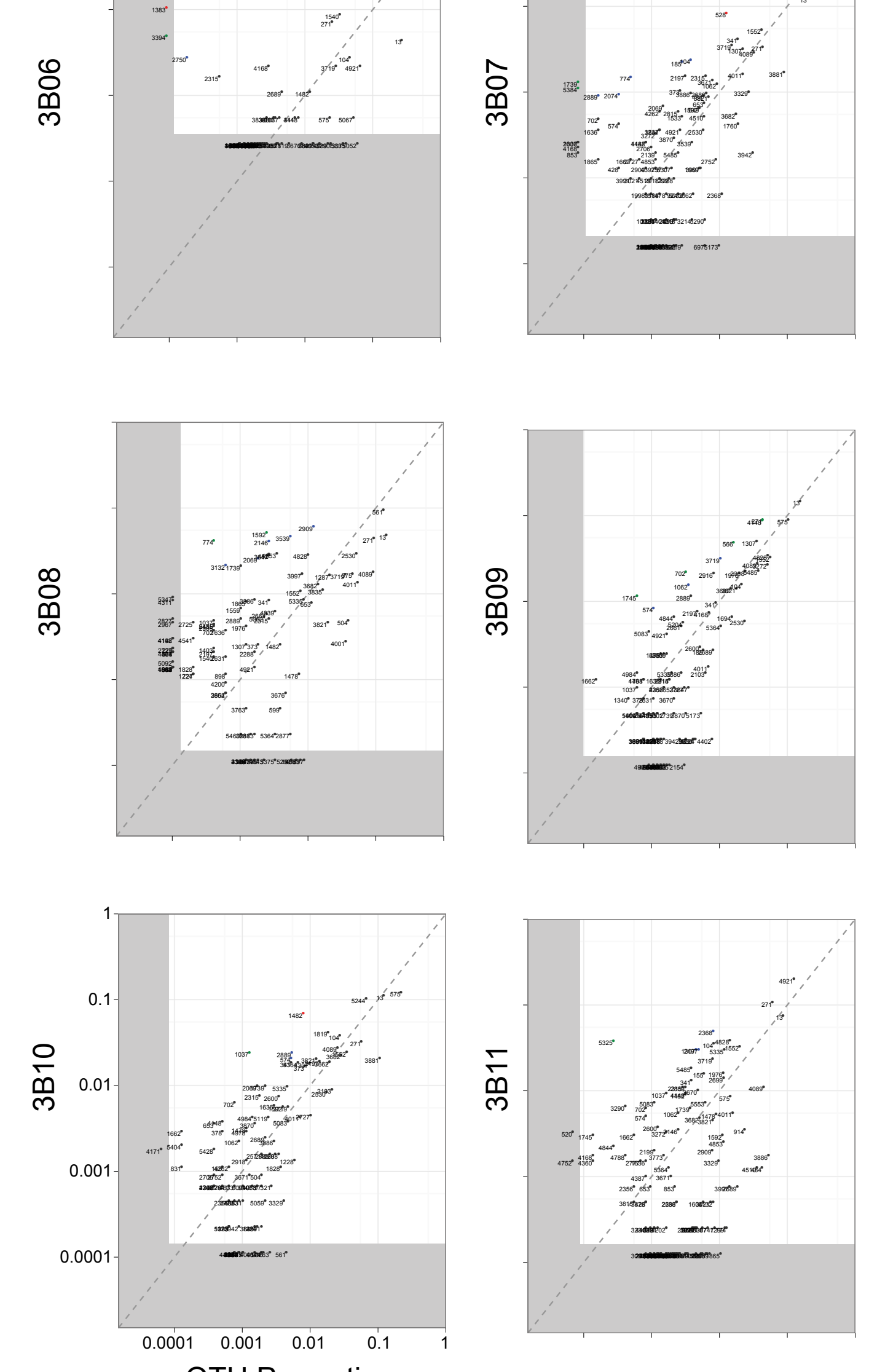
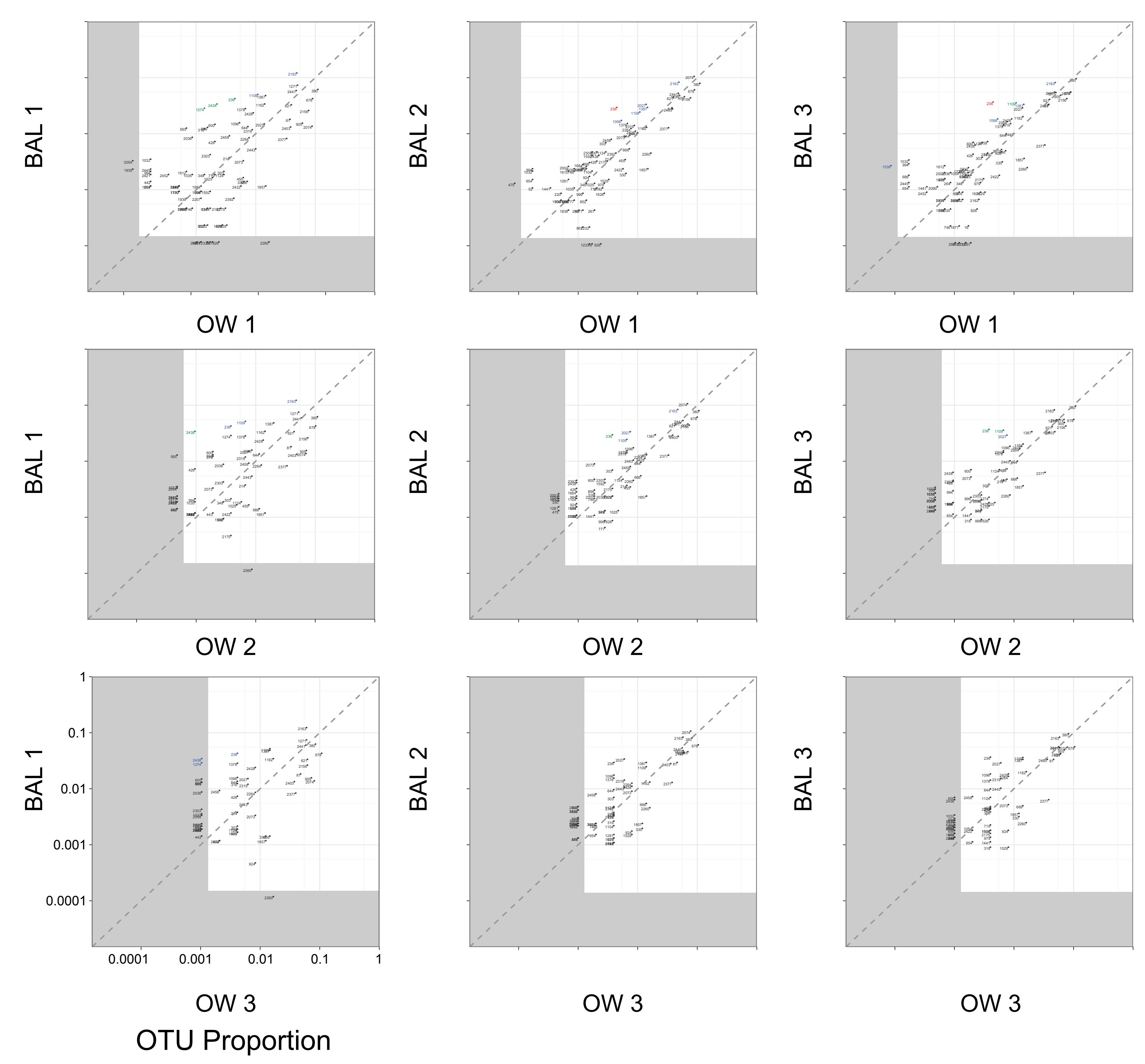

TX 43: BAL x OW
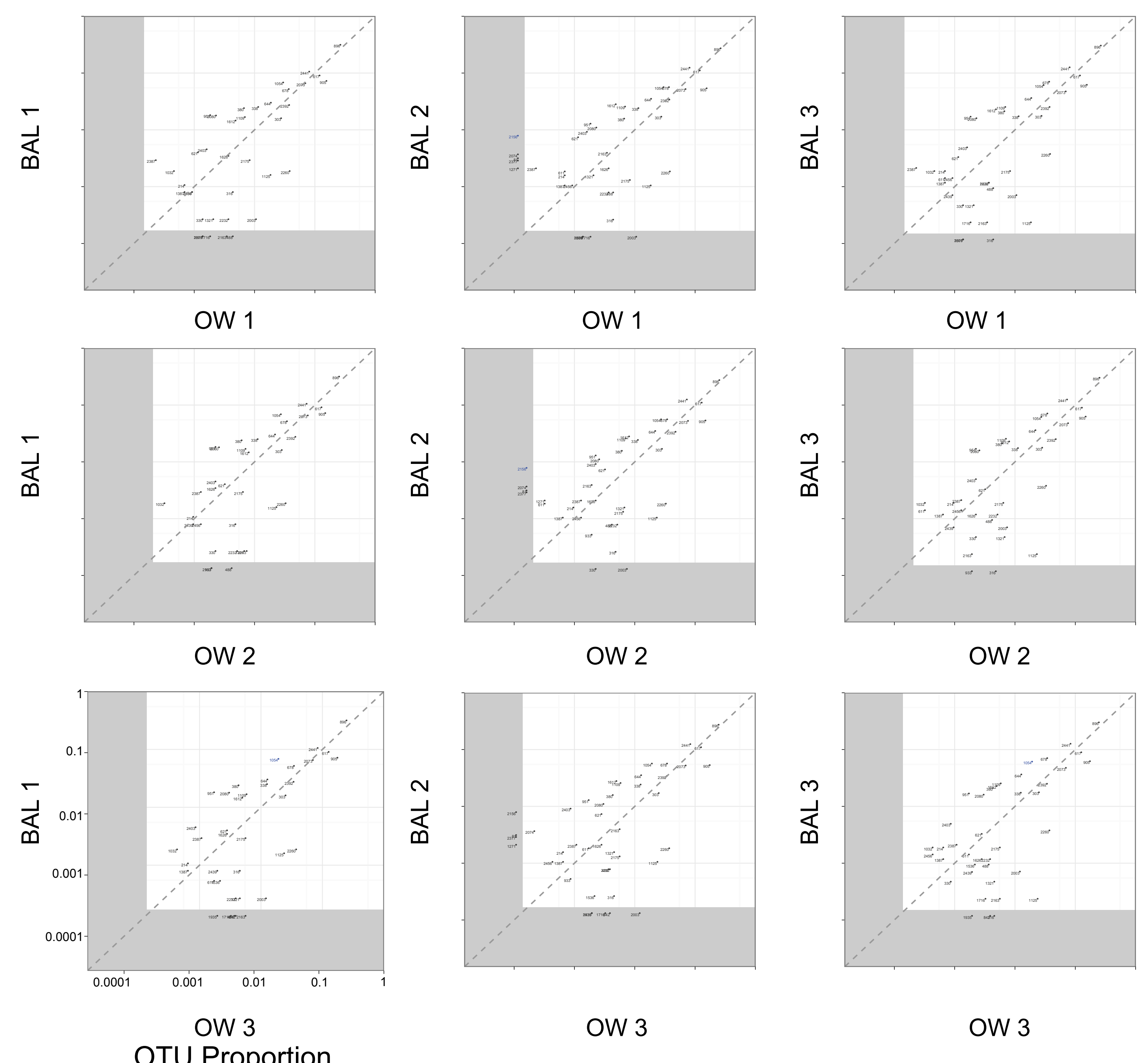

Pulm 3: BAL x OW
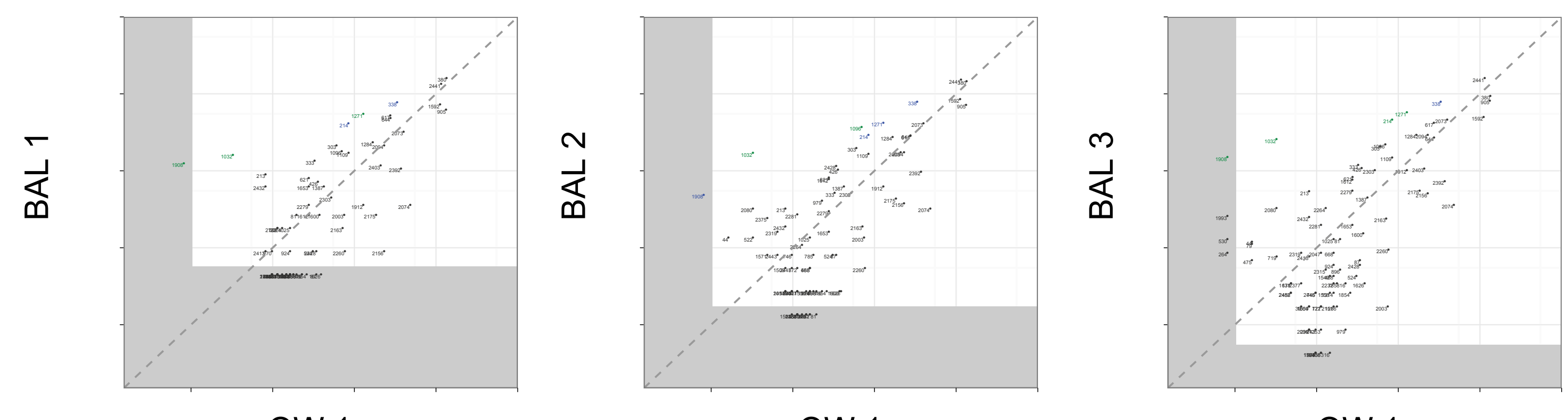

ow 1

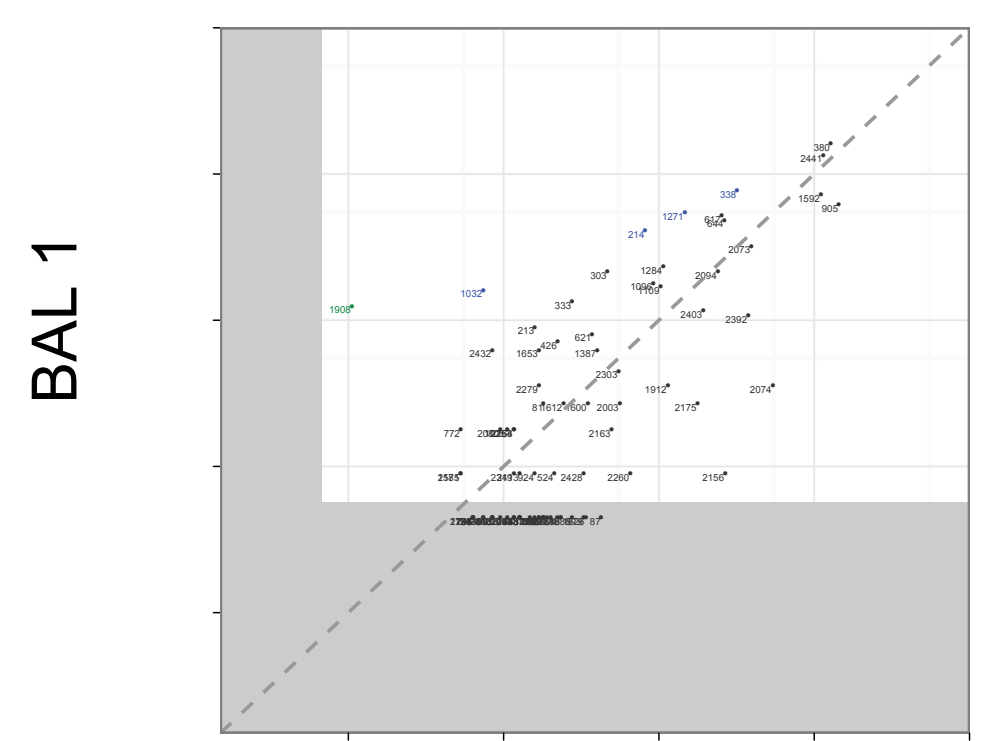

ow 2

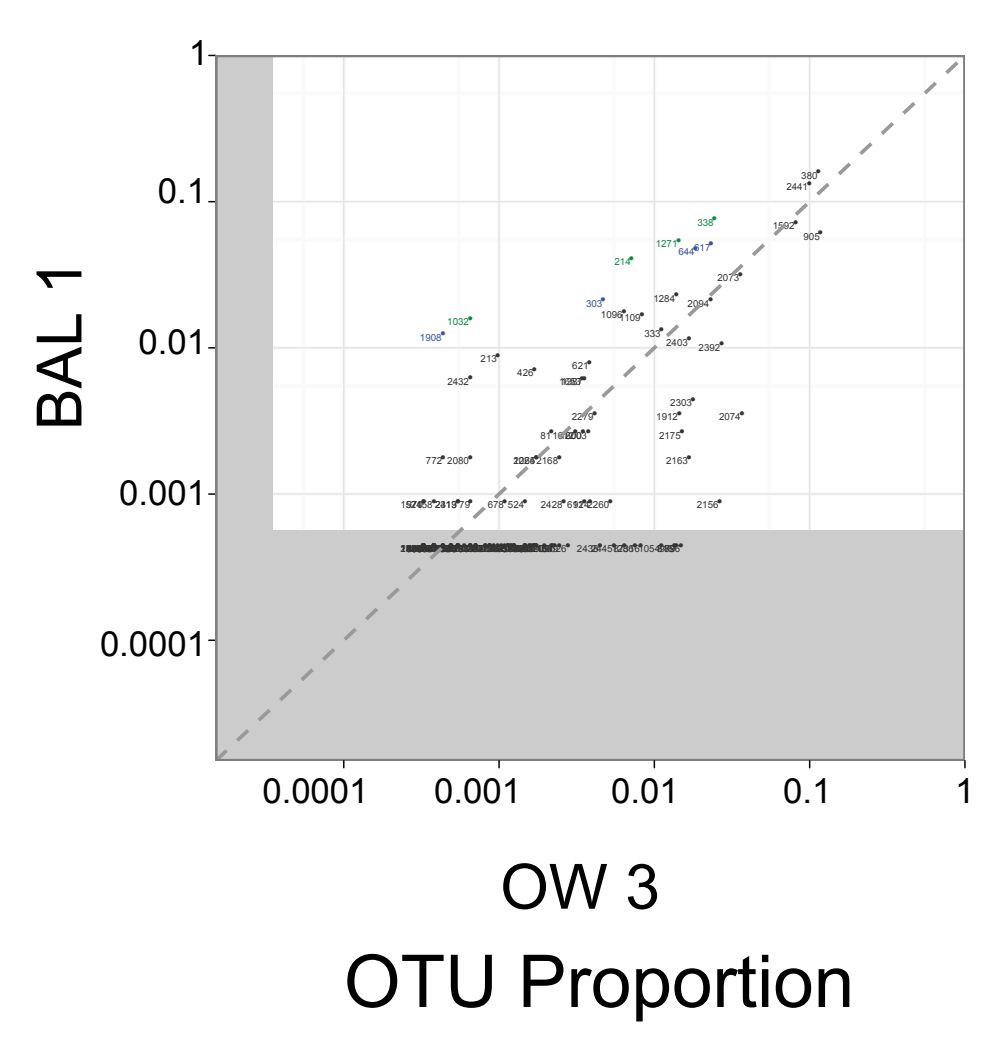

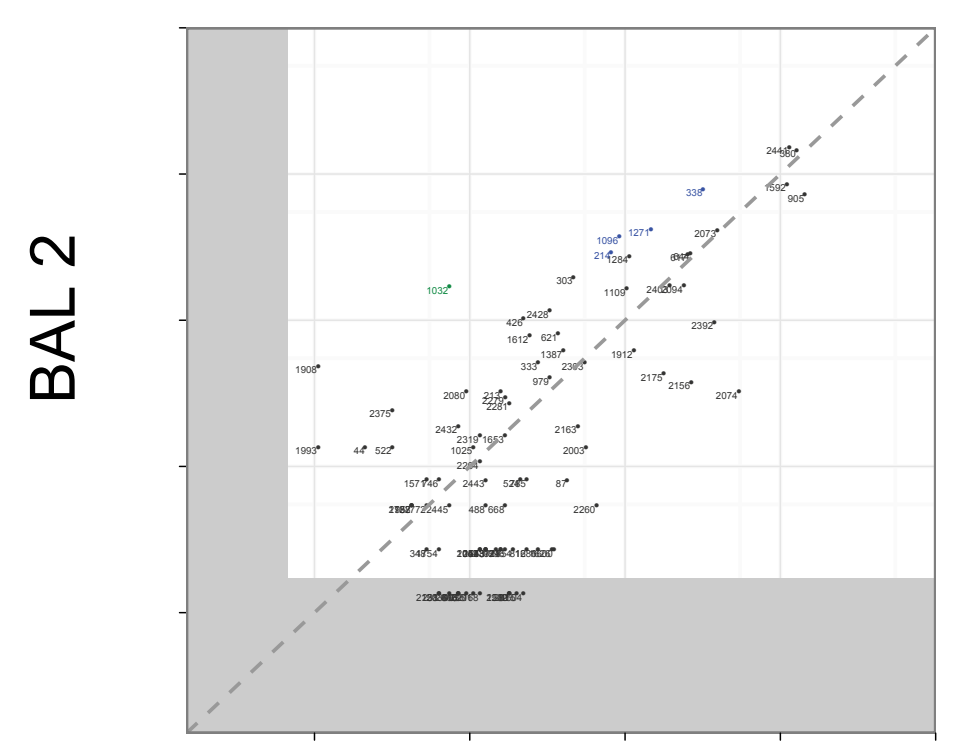

ow 2

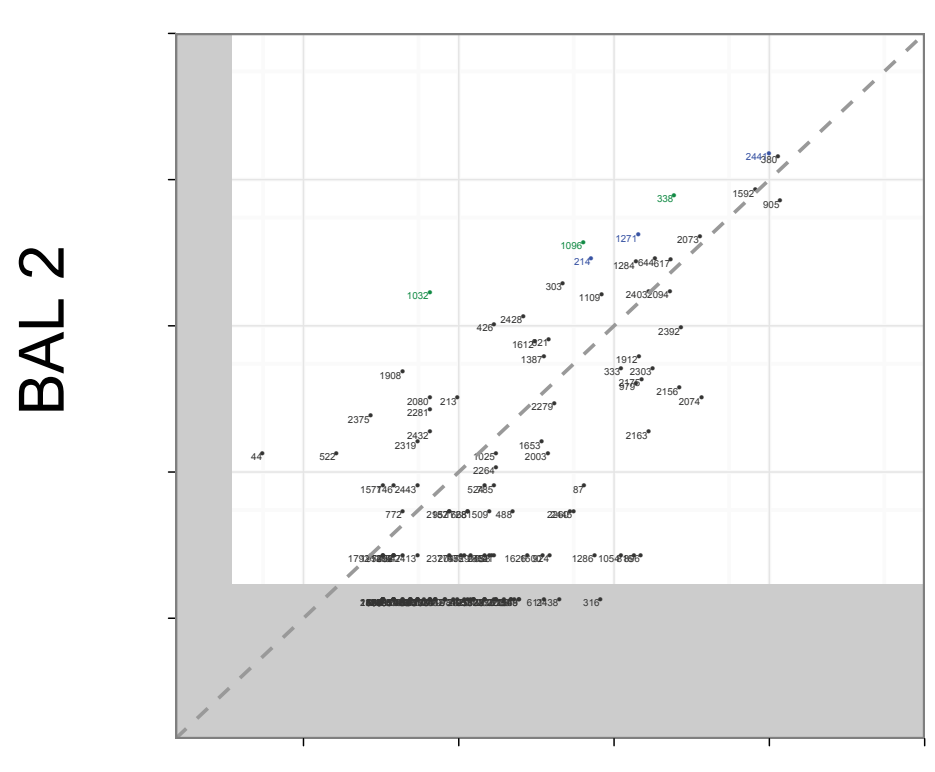

ow 3

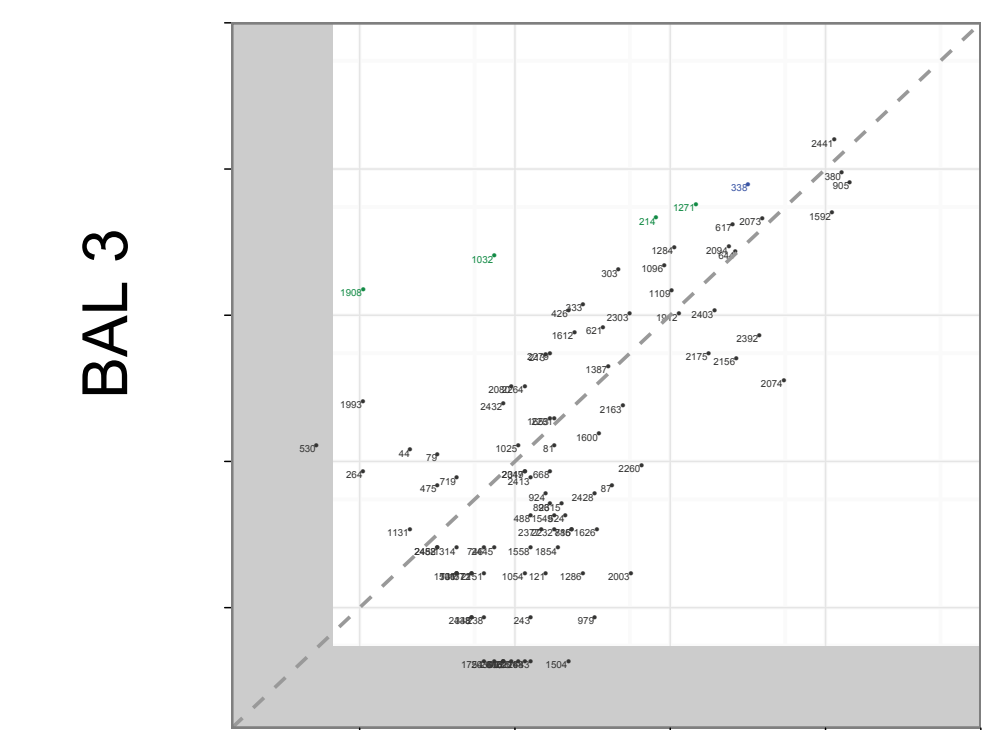

ow 2

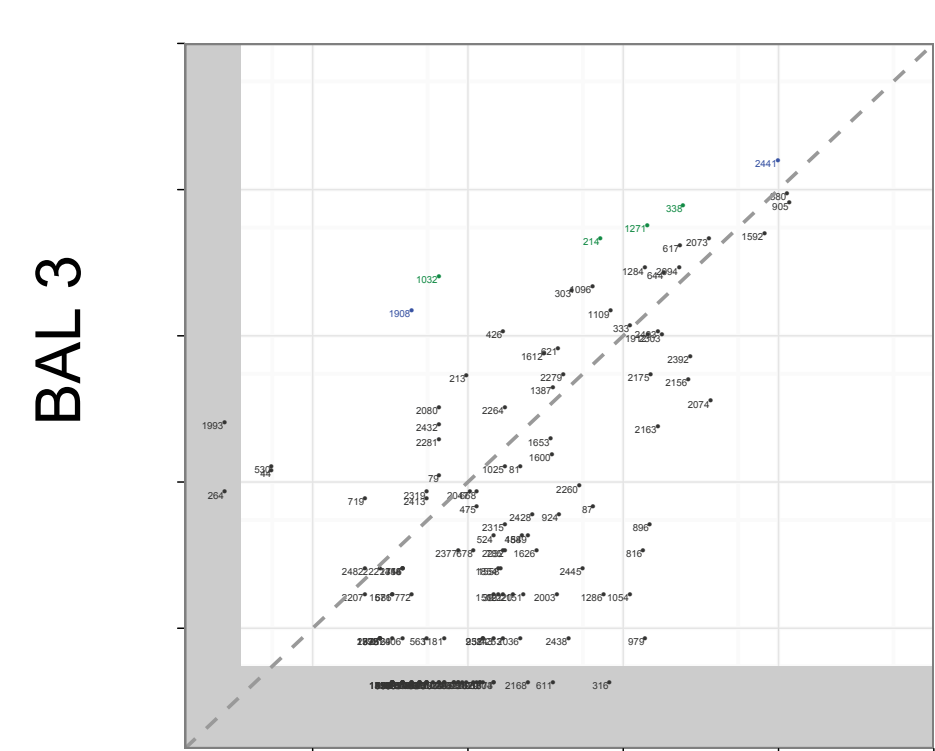

ow 3 $\overline{\bar{d}}$
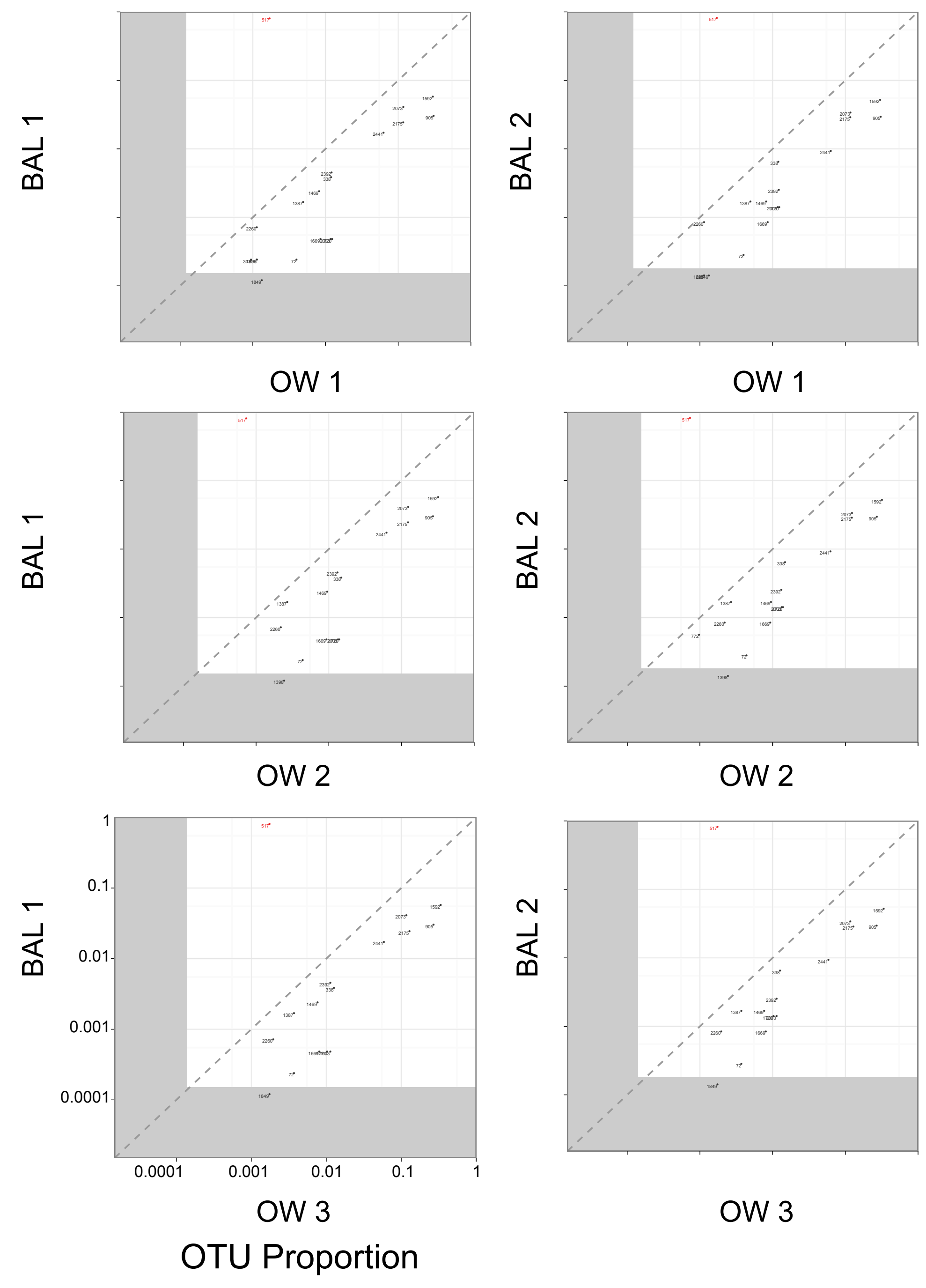

ow 3

Pulm 1: BAL x OW

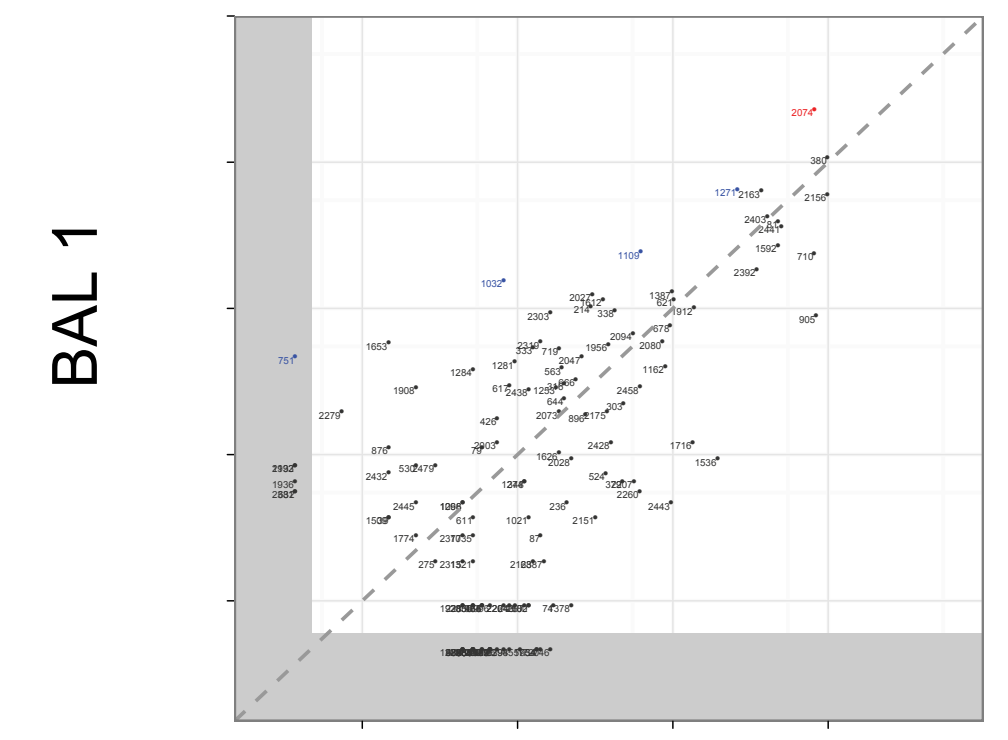

OW 1

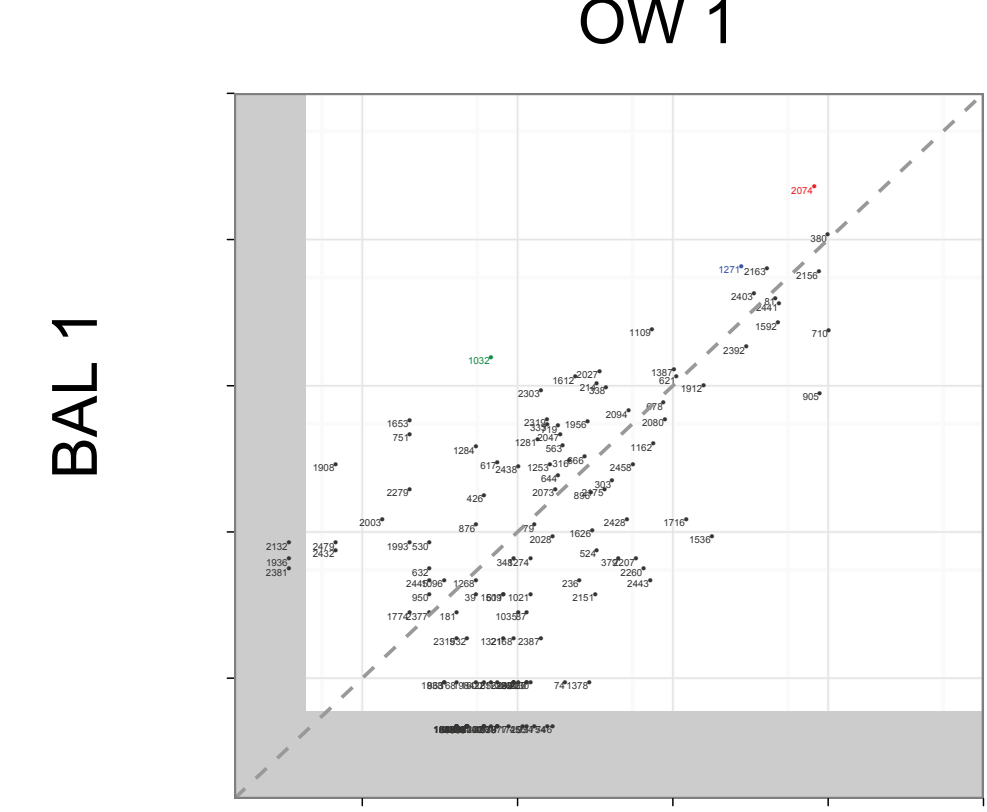

ow 2

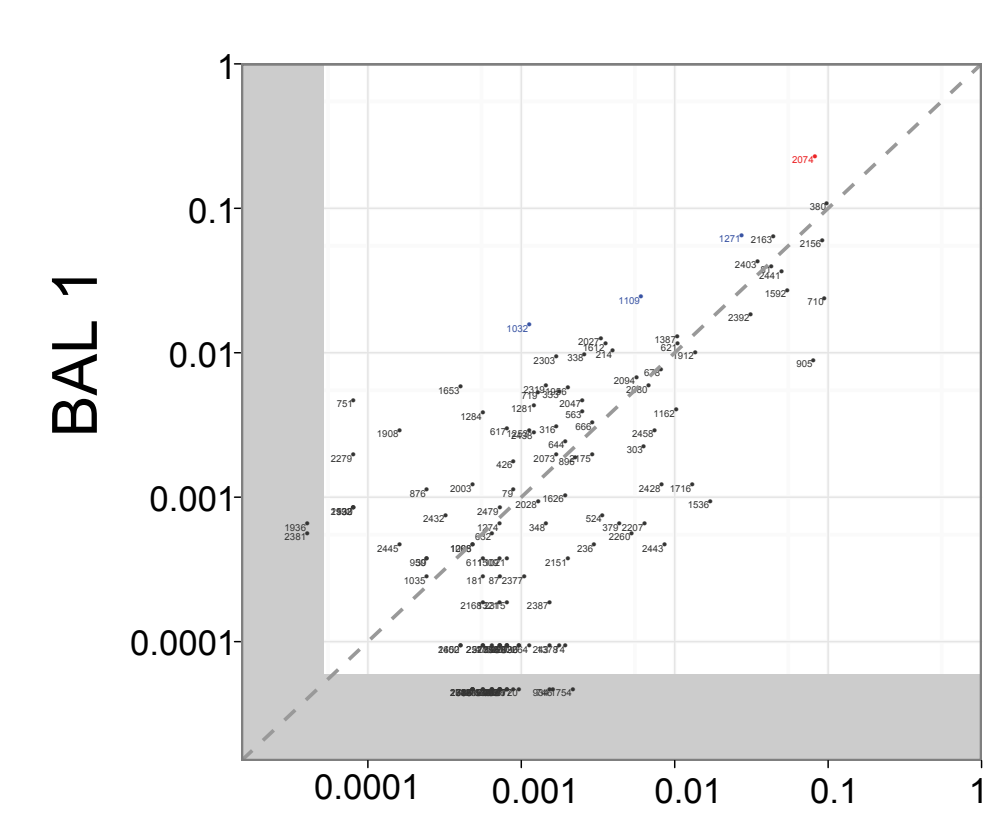

OW 3
OTU Proportion

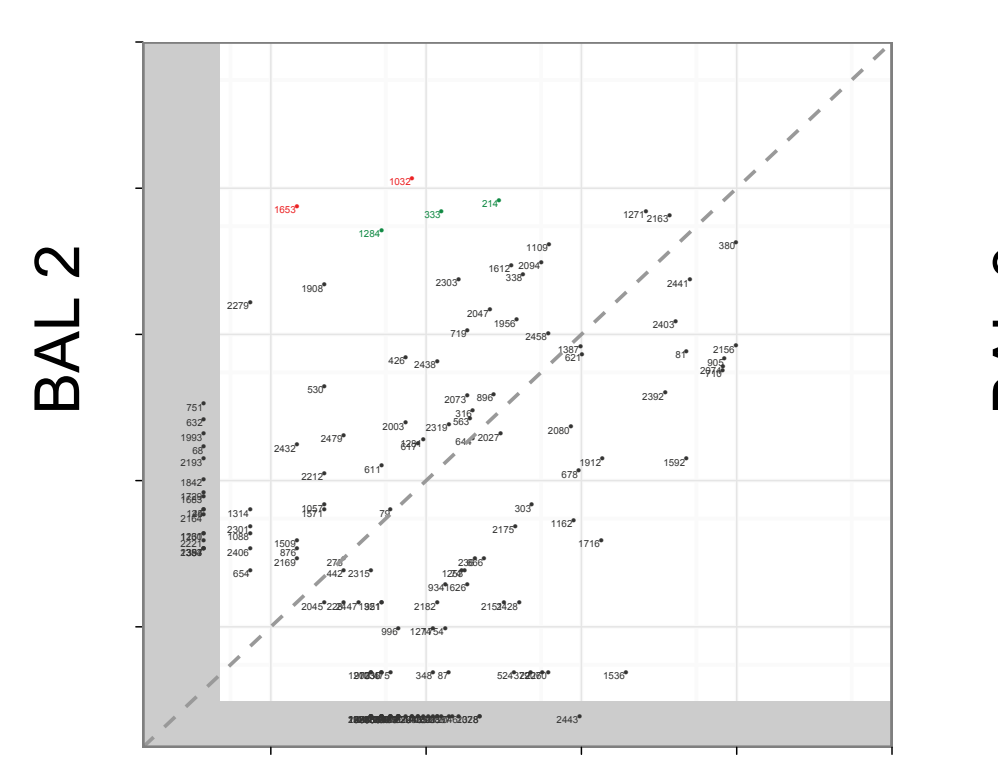

ow 1

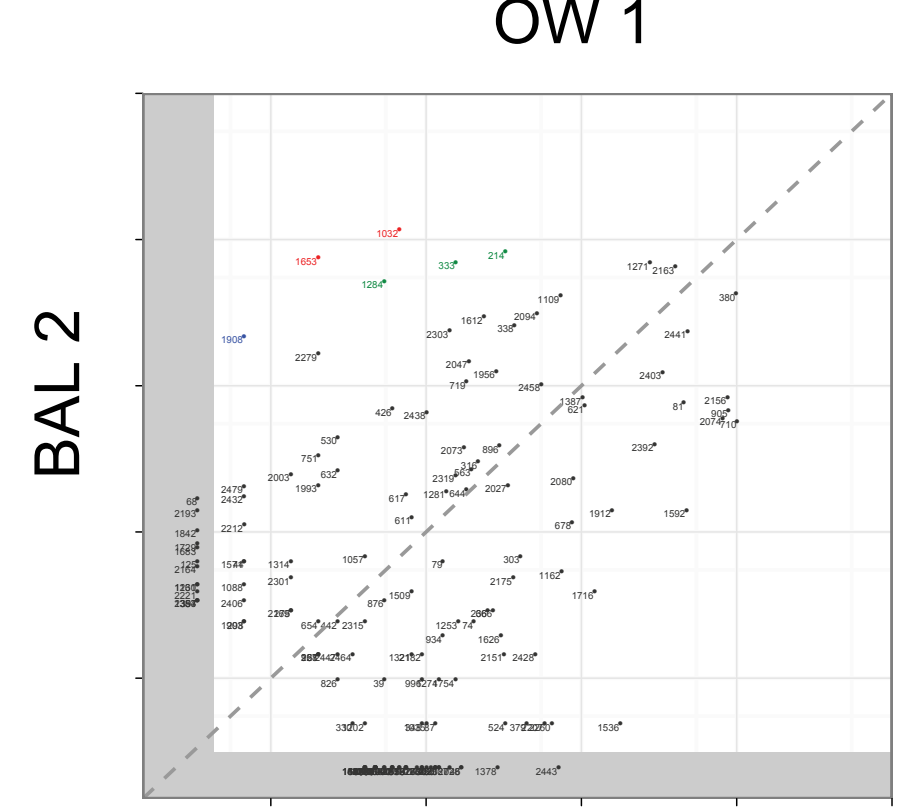

OW 2

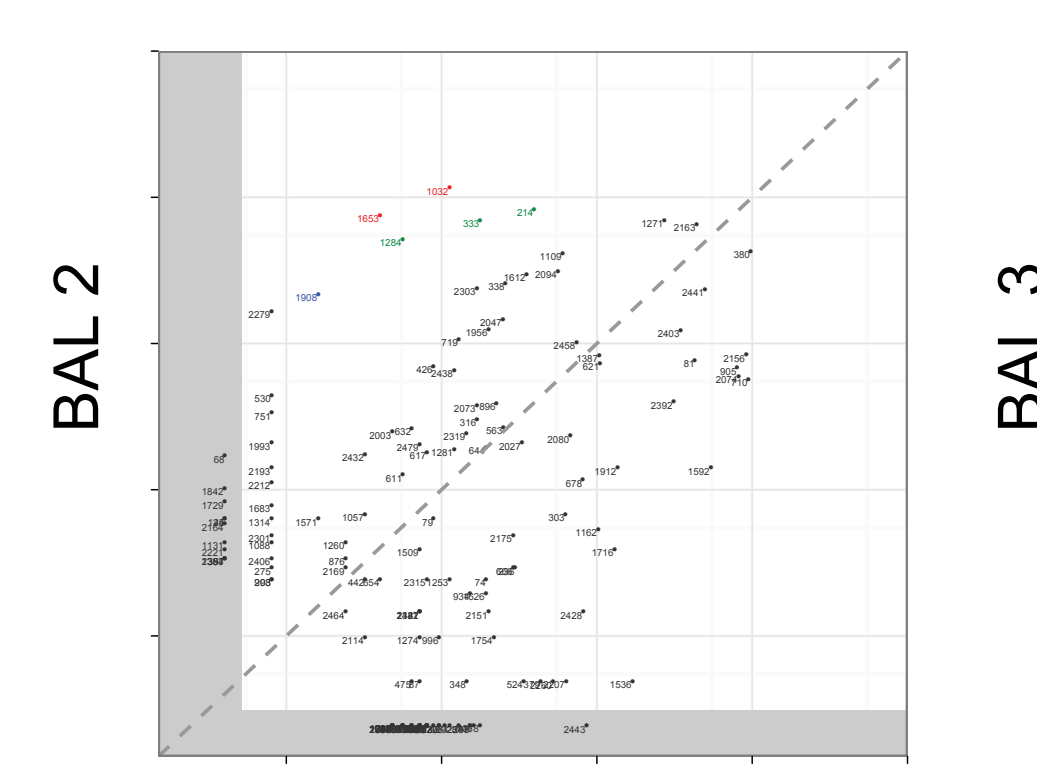

ow 3

Pulm 4: BAL x OW
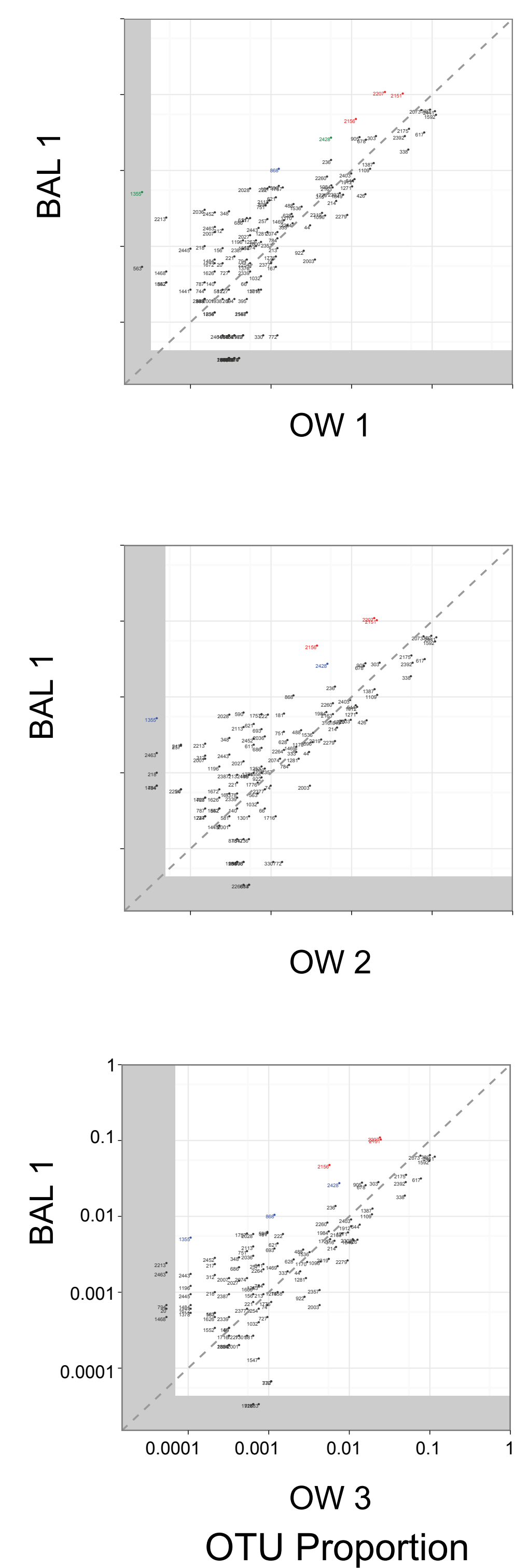

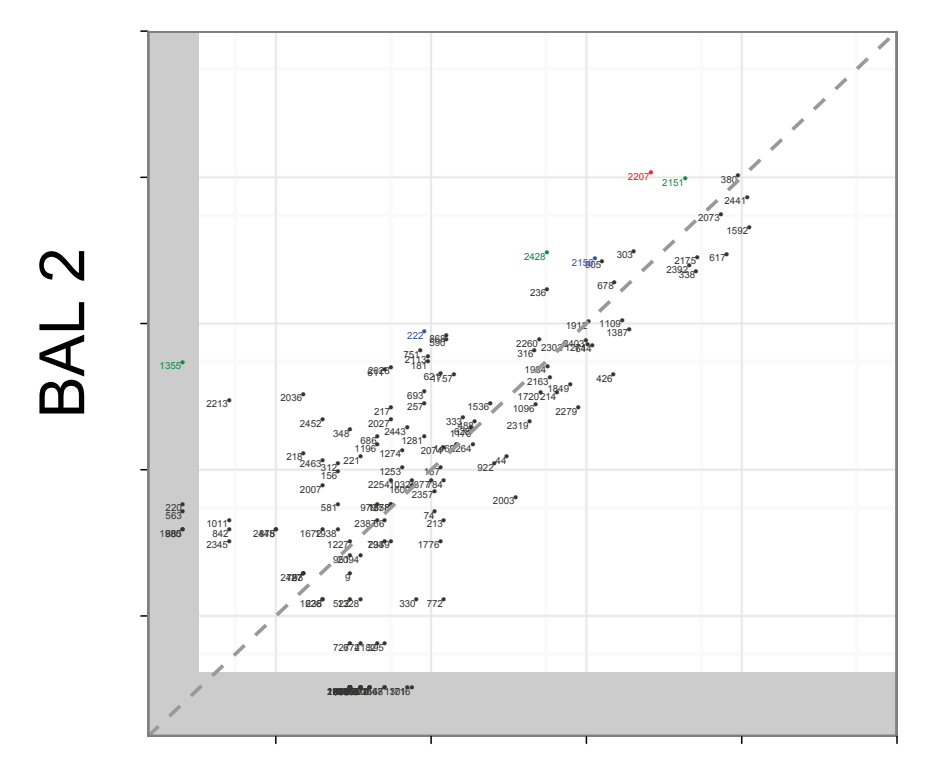

ow 1

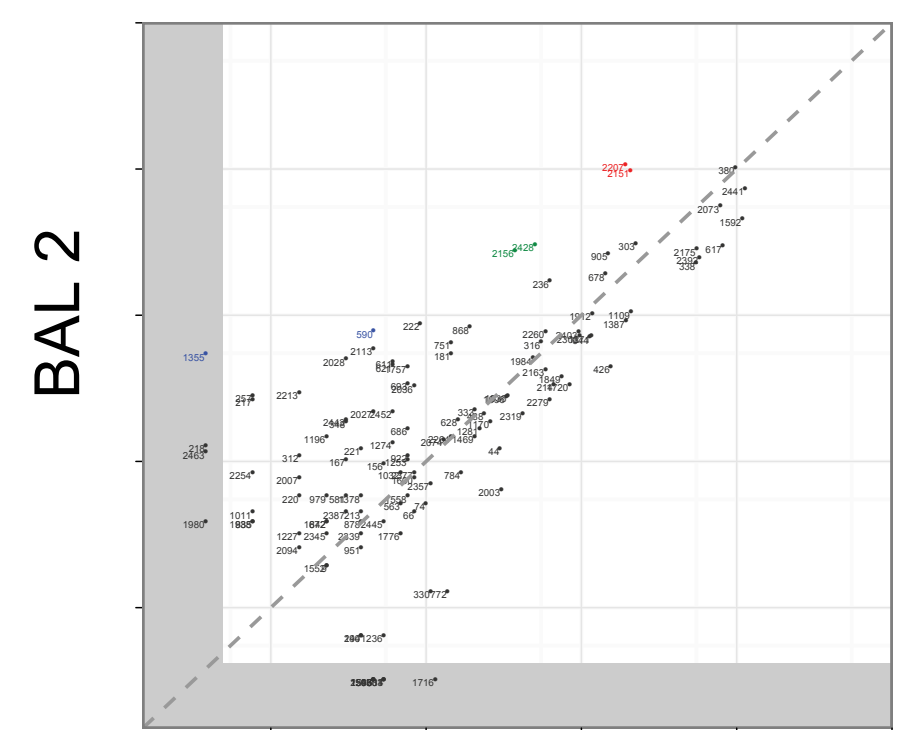

ow 2

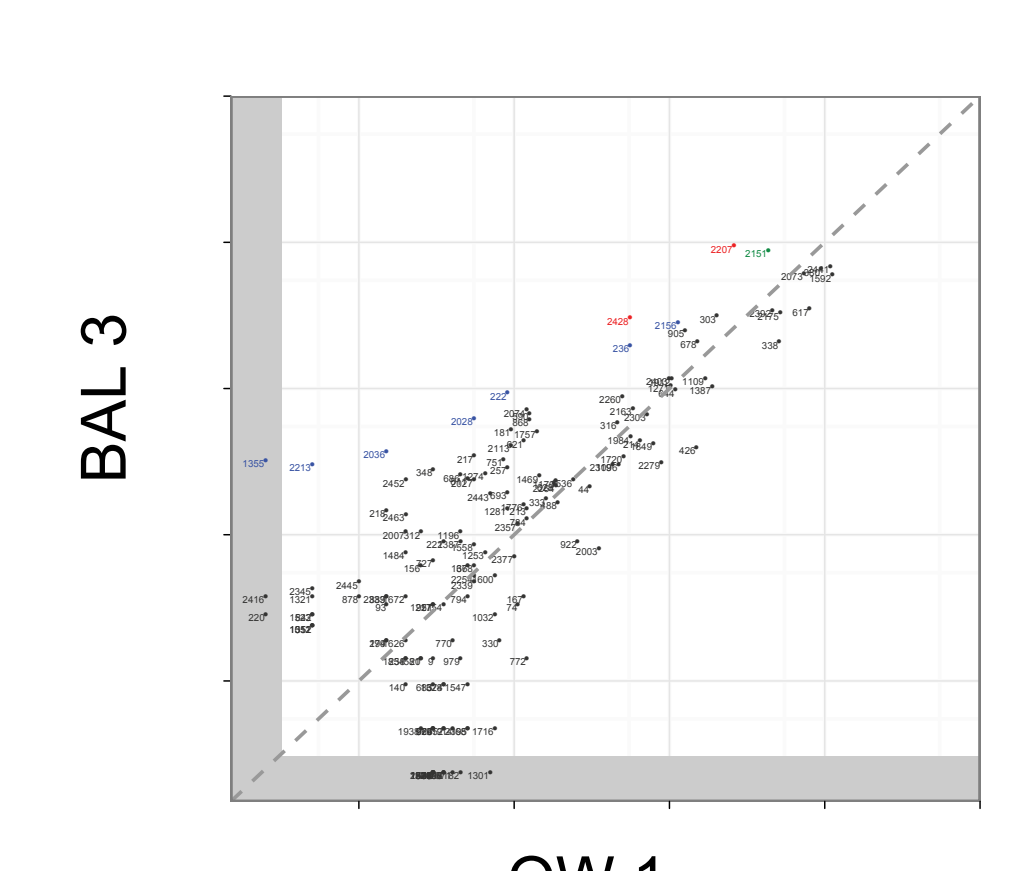

ow 1

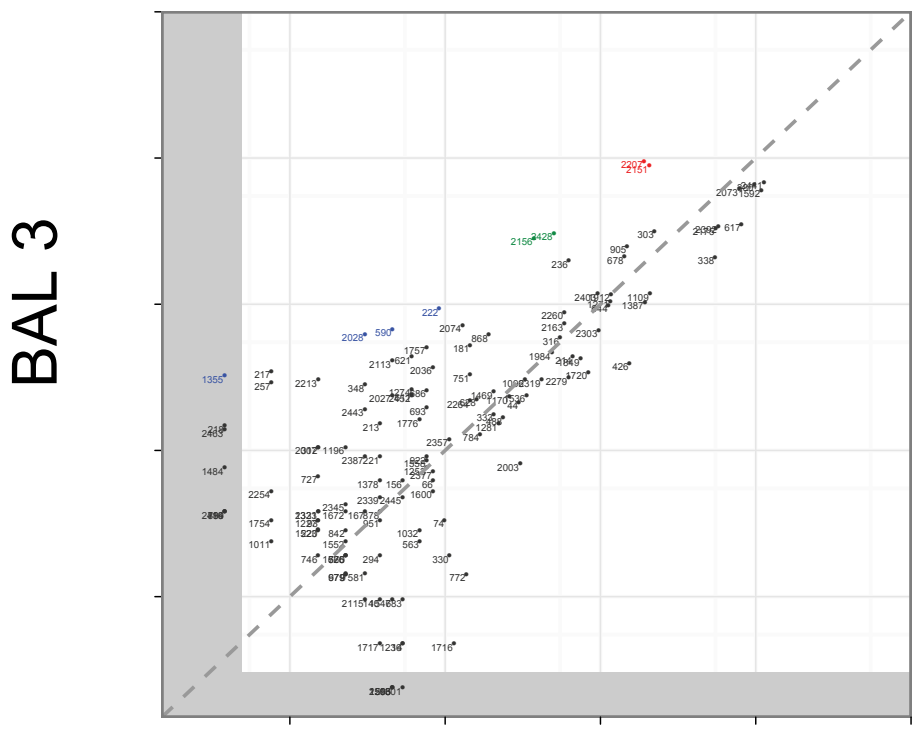

ow 2

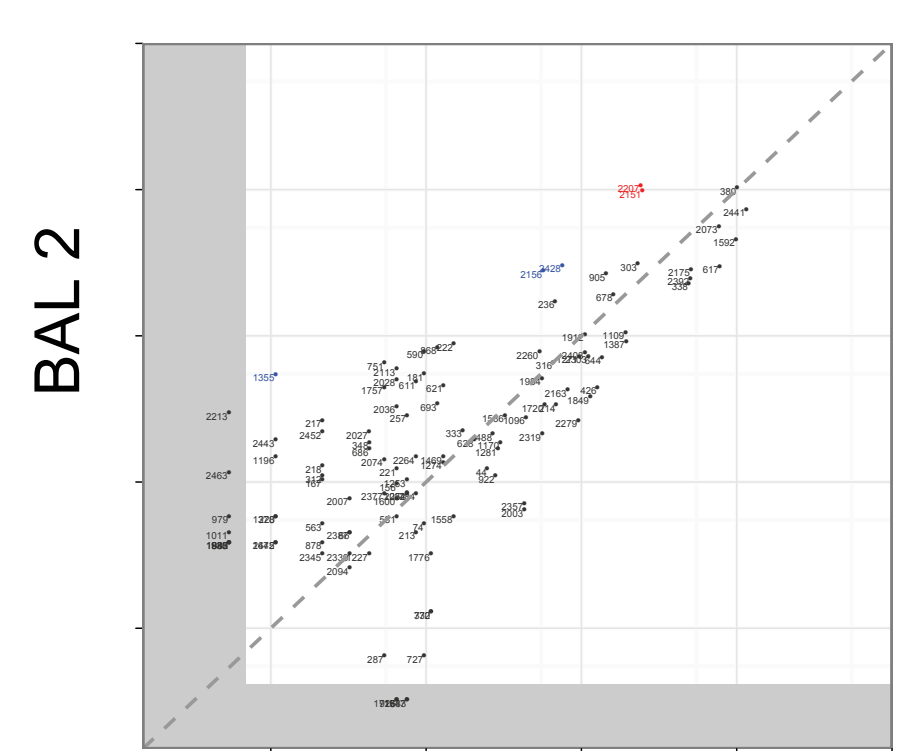

ow 3

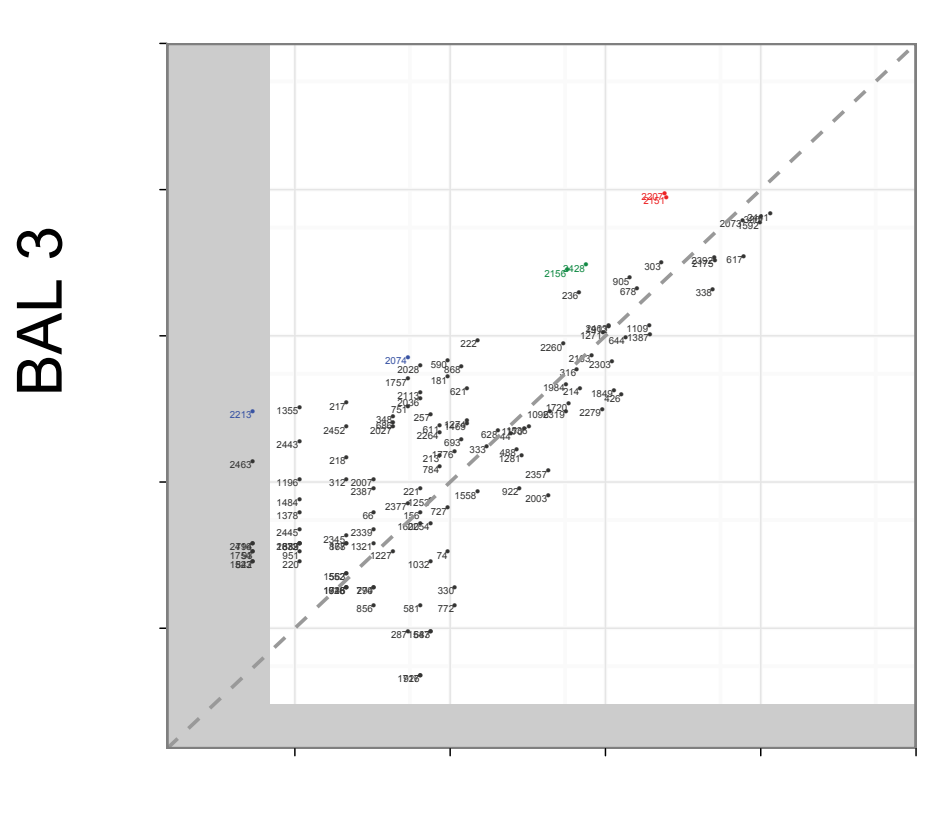

OW 3 